University of Nebraska - Lincoln

DigitalCommons@University of Nebraska - Lincoln

The Nebraska Educator: A Student-Led Journal Department of Teaching, Learning and Teacher

Education

$9-2021$

\title{
Assessments and Accommodations for English Language Learners: A Literature Review
}

Heidi Jo Bartlett

University of Nebraska-Lincoln, hjbartlett@huskers.unl.edu

Follow this and additional works at: https://digitalcommons.unl.edu/nebeducator

Part of the Teacher Education and Professional Development Commons

Bartlett, Heidi Jo, "Assessments and Accommodations for English Language Learners: A Literature Review" (2021). The Nebraska Educator: A Student-Led Journal. 60.

https://digitalcommons.unl.edu/nebeducator/60

This Article is brought to you for free and open access by the Department of Teaching, Learning and Teacher Education at DigitalCommons@University of Nebraska - Lincoln. It has been accepted for inclusion in The Nebraska Educator: A Student-Led Journal by an authorized administrator of DigitalCommons@University of Nebraska - Lincoln. 


\title{
Assessment and Accommodations for English Language Learners: A Literature Review
}

\author{
Heidi Jo Bartlett \\ Department of Teaching, Learning, and Teacher Education \\ University of Nebraska-Lincoln
}

\begin{abstract}
While research in how English language learners (ELLs) use assessment accommodations is lacking, there are some general conclusions that one can draw. First, teachers must know their students' abilities. This includes knowledge of their English proficiency, knowledge of their first language skills, especially as it pertains to literacy skills, and knowledge of their content area understanding. If teachers are aware of areas of weakness in students' assessments, they should work to compensate for them by either changing their instruction or providing assessment accommodations. Second, it is important for teachers to recognize the various types of assessment accommodations that are available in their teaching situation. More vitally, teachers must be able to assign assessment accommodations appropriately to their students and know differences between ELL accommodations and Special Education accommodations. If accommodations are applied without regard to individual student differences, it can cause more harm to the assessment procedures and evaluations than benefits. Finally, there is a difference between high-stakes standardized tests and classroom assessments. While content-area teachers may have more freedom in modifying their classroom assessments, standardized tests are usually more constrained in their testing format and accommodations they are allowed to offer. Identifying gaps in research related to assessments for ELLs will benefit the field as content-area teachers continue to increase their work with students of diverse backgrounds.
\end{abstract}

Keywords: English language learner, ELL, content area, assessment, accommodations, standardized assessments 
THE NEBRASKA EDUCATOR, VOLUME 6

Starting with the 2001 legislation of No Child Left Behind, policies determining how schools and states were required to complete their annual testing for English language learner (ELL) students changed. With these changes, ELL students had to be tested annually for their English language proficiency and progress, and this population now had to be included in the process of state standardized testing (Office of Elementary and Secondary Education: U.S. Department of Education, 2002). This requirement made states' Departments of Education determine which types of accommodations would provide their ELL students with the support to accurately test them on their content knowledge.

Updated federal policy requirements from the 2015 Every Student Succeeds Act (ESSA) expanded on school responsibilities regarding testing, data collection, professional development, and community engagement. These updated policies continue to require standardized assessment and allow specific accommodations for ELL students (US Department of Education, 2016). Additionally, according to the Supreme Court decision Lau vs. Nichols in 1974, public schools are required to provide ELLs equal access to education and the accommodations necessary to learn both English and content subjects (Office for Civil Rights: US Department of Education, 2018).

Despite the fact that these policies have been in place for nearly 20 years, there is still limited research on which types of accommodations are the most useful for different types of ELLs, and on which types of accommodations are provided by content area teachers in their daily classrooms. In order for our ELL students to be academically successful, it needs to be determined what aspects of language (either form or function) is part of the assessments. Furthermore, how is that language either taught to students or modified to be more accessible to ELLs, and are there certain types of modifications that are more beneficial to different groups of 


\section{THE NEBRASKA EDUCATOR, VOLUME 6}

ELL students? While there are still vast areas open to more research in this field, the ideas laid out below were generally consistent with other research in the field.

This literature review explores what content area teachers are doing in their classrooms to ensure the academic success of their ELLs, especially in regard to assessments. Specifically, the focus is on differences between content areas and in the types of assessments (classroom-focused and high-stakes). Most state-mandated accommodations were uniformly available to all ELLs regardless of age. This article discusses results in the content areas of reading, writing, mathematics, and science. These results will be followed by variations in language assessments and implications for teaching strategies, and then differences between classroom and standardized assessments, inquiry-based assessments, and how test translations affect student assessment.

\section{Content Areas}

\section{Reading}

"One important challenge that we face in education is to identify which core set of language skills students know or do not know" (Uccelli \& Phillips Galloway, 2017, p. 397). This problem of identifying students' prior knowledge and how to test content skills rather than English ability runs throughout much research in working with English Language Learners. One of the most basic skills and content areas found in all U.S. classrooms is reading. As a literacy skill, having greater vocabulary recognition and knowledge helps students to become more fluent readers.

In their study, Dougherty Stahl and Bravo (2010) examined vocabulary tests and utilized pre-tests and post-tests to determine what it means to "know a word" (p. 567). They utilized a self-reporting scale with students that included categories such as 1) I haven't seen this word, 2) 


\section{THE NEBRASKA EDUCATOR, VOLUME 6}

I have seen this word, 3) I have seen this word and know a synonym or definition, and 4) I have seen this word and can use it in a sentence (Dougherty Stahl \& Bravo, 2010). Having students self-report their comfort level with lesson vocabulary words can indicate to teachers students' background knowledge and identify areas of potential difficulty.

One of their conclusions was that teachers have to know what the important content information and vocabulary are in order to determine what students know (Dougherty Stahl \& Bravo, 2010). Despite this conclusion, some content-area teachers may not be aware of their lessons also having a linguistic component as well as the content component. The authors recommended that teachers work with their colleagues to identify key words, concepts, and new vocabulary for their units as they plan their teaching (Dougherty Stahl \& Bravo, 2010). This suggestion is applicable to content areas outside of reading, as well. However, if teachers are unable to identify - either through teaching experience or through prior feedback/assessments with students - which words are unknown to students, this task becomes much harder and more ineffective for learning. Explicitly addressing key terms that may be unknown to ELLs is an accommodation that can help increase student scores in later assessments.

Other researchers agree that applying both direct and indirect linguistic support as a next step after identifying problem areas can be beneficial. According to Shafer Willner, Rivera, and Acosta (2009), “Accommodations for ELLs involve changes to testing procedures, testing materials, or the testing situation to allow students meaningful participation in an assessment" (p. 697). Based on recommendations from classroom teachers and ELL teachers, teams should make accommodation decisions to support individual students' linguistic needs, and those accommodations (such as dictionaries) should be introduced and/or taught to students before the test (Shafer Willner, Rivera, \& Acosta, 2009). 
THE NEBRASKA EDUCATOR, VOLUME 6

\section{Writing}

While reading and writing are language domains along with speaking and listening, here they are classified under the heading of content areas to reflect their focus in research. A consideration for validity in testing is whether the accommodations can provide unfair advantages to specific sets of students.

In a study by Oh (2020), the researcher posited that ELLs should be allowed to use writing tools such as dictionaries and spell-checkers during their writing assessments, as it more accurately reflects real-life and academic situations where those tools are widely available for their use. This study found that students of differing English language proficiency levels who had access to those tools still showed the differences in their levels while creating more accurate writing with more confidence. In other words, simply by providing more resources, student's abilities were not artificially inflated. In the survey administered after the two writing tasks, the majority of the students (35/39 total students) agreed with the statement "I think having access to the tools gave me the chance to show how well I can write in English", while some other students expressed concerns about perceived test fairness. In fact, the use of resources during the writing assessment actually provided more accurate writing that showcased what the student was able to do in realistic settings at their differing English proficiency levels (Oh, 2020).

In a rare study that compared ELL and non-ELL high school students in New York City, the researchers acknowledged that academic writing is a learned skill that traditional assessments (writing prompts with holistic grading) do not do enough to facilitate students' future learning (Llosa, Beck, \& Zhao, 2011). One of their findings concluded that, while teachers assign and work on a variety of writing genres throughout the school year, the writing prompts given as part of high-stakes assessments were much narrower in scope. If teachers were more aware of this, 


\section{THE NEBRASKA EDUCATOR, VOLUME 6}

they may be able to concentrate on the linguistic variation and expectations for the genres most frequently found on high-stakes tests (provided that passing such tests is one of the goals of the course). Given that many teachers do not analyze their tests to this degree, providing professional development in the areas of assessment literacy or linguistic expectations could improve student test results, especially for ELLs.

When the researchers employed a think-aloud protocol as students completed an exposition writing task, their interviews found that students identified "translating", or finding the right words for the essay, as overwhelmingly the most prevalent problem, with $90 \%$ of ELLs and $82 \%$ of non-ELLs reporting this. However, the distinction between the two groups was that "for ELLs more than for non-ELLs the challenge of finding appropriate words was more likely to prevent them from writing at all, or to force them to completely change their approach to articulating an idea" (Llosa et al., 2011, p. 268). Therefore, when thinking about assessments for high school students and writing, allowing the students the use of dictionaries (both bilingual and monolingual) during the task may be beneficial. Additionally, as supported by Dougherty Stahl and Bravo (2010), spending more instruction on using vocabulary in context may alleviate some of the translation issues that students encountered.

Another study led by Uccelli and Phillips Galloway (2017) worked with upper elementary and middle school students as they viewed this same question from a different viewpoint. When the researchers used their own assessment tool that focused on academic language, they concentrated on how students view language. Based on their ideas, and on feedback from students about the perception of their skill with academic language, teachers need to consider how they can leverage what skills the students have, regardless of whether they are strong in those skills or lacking them. Since reading and writing are used throughout education in 
THE NEBRASKA EDUCATOR, VOLUME 6

both learning and assessment, if student acquire those literacy skills, they will transfer into other academic areas as well.

\section{Mathematics}

One area of difficulty in working with ELLs in the content areas is the acknowledgment that there are multiple types of learning occurring at the same time. Unfortunately, some view mathematics as a "language-free" subject, thus ignoring the linguistic challenges that are present. "To achieve success [...], EL students must learn both mathematics and English simultaneously. This means that a teacher who has EL students in his or her classroom is not only a mathematics teacher but also a language teacher" (Leith, Rose, \& King, 2016, p. 670). However, many content-area teachers are not taught about the differences between linguistic knowledge and content knowledge, as teacher preparation programs in approximately 35 states require no specific coursework in working with ELL students (Education Commission of the States, 2014). Despite this lack, to provide appropriate testing accommodations for languages, teachers must evaluate students' content knowledge and be on the watch for test items that provide linguistic difficulty, such as polysemous words. This corresponds with conclusions drawn by Dougherty Stahl and Bravo as stated above. Vocabulary should be explicitly taught and practiced, especially those words that students will encounter on assessments. Overall, mathematics teachers need to be aware of the traps ELL students fall into and think about how they will modify their content to reach the students where they are at with the goal of moving them forward - both language-wise and mathematics-wise (Leith, Rose, \& King, 2016).

Schleppegrell (2007) supported this idea that mathematics vocabulary is important to explicitly teach, as well. In math, there is a variety of ways for students to receive information that involves many components of language. To be successful, students need to know math 


\section{THE NEBRASKA EDUCATOR, VOLUME 6}

jargon, graphic depictions of mathematical concepts, connections between ideas, and how to communicate their understanding of the theories and practical applications. Therefore, as a teaching or testing accommodation, teachers should be prepared to address these various components to help students advance from everyday use of vocabulary to their math-specific meanings (Schleppegrell, 2007).

In another study focusing on mathematics, researchers utilized survey responses along with some follow-up interviews to determine what teachers are actually doing in state mathematics ELL assessment accommodations (Wolf, Kao, Rivera, \& Chang, 2012). Eighthgrade math and ELL teachers were studied and the research included 165 respondents from two states, responding on high-stakes assessment from the 2007-08 academic year. Testing and accommodation decisions were often made by a team, but the makeup of the team varied between schools. "The authors' analysis revealed that most states did not focus on the unique linguistic needs of ELL students, making little distinction between ELL students and students with disabilities regarding test accommodations" (Wolf, Kao, Rivera, \& Chang, 2012, p. 3). Whole-class accommodations instead of individual accommodations were frequently applied due to logistics such as the lack of testing space or proctors.

ELL teachers and math teachers rated different types of accommodations as the most helpful, and other types of supports were mixed. An exception was the use of an English-only dictionary and a glossary, which were marked as among the least useful by both ELL and math teachers. Overall results promoted the belief that states should provide guidelines for ELL testing supports which are separate from IEP or 504 supports, and training should be provided for those responsible for making accommodation decisions. While IEP and 504 supports are determined by a team of involved professionals on an individual basis for each student with parent and 


\section{THE NEBRASKA EDUCATOR, VOLUME 6}

teacher inputs, the process to determine ELL testing supports, as evidenced by this study, are applied much more uniformly. From these results, all teachers that are involved in assessments should be made aware of the types of supports that are permitted and should work together to determine which assessments benefit students the most.

In another study, the researchers determined that accommodations on standardized assessments were most beneficial when students were aware of the social and academic content (Wolf, Kim, \& Kao, 2012). For the $8^{\text {th }}$ grade students in this study, this referred, too, to life situations, such as tipping at a restaurant, that students may not have understood as a societal concept before taking the assessment. Therefore, accommodations such as reading the test aloud to students becomes less useful if the overall context of the scenario being presented is a new one to students (Wolf, Kim, \& Kao, 2012), and should be considered by teachers who want to assess students content knowledge.

This conclusion aligns with those by Monarrez and Tschoshanov (2020) which state that the information being taught in the mathematics classroom must be converted to a way that is clear for students. Since student learning is dependent on teachers' abilities to translate new concepts to ELL students, teachers should be willing to provide information in multiple ways, such as using simplified language (Monarrez \& Tchoshanov, 2020). Expecting ELL students to be academically successful without using accommodations at the same level as non-ELL students is an expectation that is not often borne out.

\section{Science}

Like mathematics, the subject of science also faces linguistic and cultural challenges along with content. To support students, assessment should include visuals such as diagrams and 


\section{THE NEBRASKA EDUCATOR, VOLUME 6}

graphs. However, accommodations in science can go beyond direct linguistic supports and involve changes in how the test is designed.

Students need variety in test question types and opportunities to share their ideas in more formats than simply multiple choice. Teachers and test-designers should allow variety in answers while encouraging use of scientific discourse. Researchers claimed that the use of constructed response items helped "ELLs demonstrate their scientific knowledge on science assessments by allowing them to articulate ideas and justifications in their own words" (Turkan \& Liu, 2012, p. 2365). By allowing different types of responses, students are able to exhibit their understanding while compensating for smaller linguistic or grammatical errors. Additionally, within the classroom, teachers should ensure that they provide opportunities for ELL students to speak about what they're learning. Teachers should consider what is involved in the language of evaluation to ensure students know how to interpret rubrics and project guidelines (Bunch, Shaw, \& Geaney, 2010).

As a part of classroom assessments, inquiry assessments are especially useful in science, as students need access to the higher-level thinking and skills that such assessments provide (Turkan \& Liu, 2012). Students need to be able to apply information and justify their educational decisions in constructed responses. In this study, ELLs ( $n=313$ students) were significantly outperformed by non-ELLs ( $\mathrm{n}=1083$ students) in a computer-administered low-stakes test in a $7^{\text {th }}$ and $8^{\text {th }}$ grade life science course in 10 schools in California with an overall rate of $22.5 \%$ ELL population. While most items favored non-ELLs, there was one test item that favored ELLs, which may have been due to the additional visual support of a graph (Turkan \& Liu, 2012).

Despite these results that might appear negative, providing space for students to explain their ideas allows for cultural differences and variety in approaches to the same problem, thus 


\section{THE NEBRASKA EDUCATOR, VOLUME 6}

making it more likely that ELLs are able to share their understanding to the maximum extent possible given their linguistic constraints. If students are provided with only closed-response options, teachers are not able to investigate to determine the students' level of understanding. On the other hand, open-response, or constructed response questions (with visual and linguistic supports) can be more accurate indicators of how students are incorporating science information into their schemas.

Bunch et al. (2010) classified the type of language demands in science assessments to fall into three categories - participant structures, communicative modes, and written texts and genres. "The language demands of instruction and assessment in inquiry-based classrooms using performance assessment could present opportunities for students to develop a wider repertoire of language skills than would be present in classrooms focused on preparation for more traditional assessments” (Bunch et al., 2010, p. 205). From their conclusions, Bunch et al. (2010) emphasized that if classroom teachers are requiring students to explain their ideas and the process they utilized to develop their results, then those skills must be practiced and scaffolded for all students, and especially ELLs. Therefore, if constructed responses are more widely utilized, as Turkan and Liu (2012) recommend, then that is a linguistic skill that ELLs need to be taught.

Another aspect of assessment in science is considering test item linguistic simplification (Rivera \& Stansfield, 2004). In this study, Limited English Proficient (LEP) (n=108) and nonLEP students (nearly 11,200 in $4^{\text {th }}$ and $6^{\text {th }}$ grade) in Delaware were provided with a science test. Within the larger test, there was a subset of either simplified or regular questions that tested the same content. At the time of the test, most LEP students did not receive any testing accommodations. Analyzation of the short-answer and multiple-choice question results for the 
THE NEBRASKA EDUCATOR, VOLUME 6

state science assessments showed that the non-LEP students did not receive an unfair advantage in testing by providing test items using simplified English. Unfortunately, the number of LEP students was too small to make a generalization (Rivera \& Stansfield, 2004).

Therefore, test developers should consider that since the simplified test items did not provide an advantage or disadvantage to the non-LEP students, and could potentially provide more accurate results for LEP students, more simplified test items should be included in future tests. However, knowledge of linguistics and ELLs are needed to determine how best to simplify test items while still maintaining academic rigor, especially in states and content areas where ELL students are a larger percentage of the general school population.

\section{Additional Considerations}

\section{Standardized Assessments}

Apart from focusing on content areas, some research investigated how ELLs were affected by the type of assessment. For example, standardized assessments, classroom assessments, and inquiry or performance-based assessments would all have different types of modifications that might be beneficial to ELLs.

Standardized tests are commonly administered on an annual basis in all states. However, the standardized test itself, as well as their allowed accommodations, differ widely among states, districts, and schools. While classroom teachers may not make the initial decision about the general types of accommodations that are allowed by the testing company, they often influence the actual accommodation provided to the students.

Overall results stated that accommodations that were incorrectly provided to students were no more beneficial than having no accommodations provided at all (Kopriva, Emick, Hipolito-Delgado, \& Cameron, 2007). Therefore, Kopriva et al. (2007) suggested common 


\section{THE NEBRASKA EDUCATOR, VOLUME 6}

accommodations for standardized tests include translating tests into the L1, providing extra time, having the test read aloud, and using bilingual dictionaries, picture dictionaries, and word lists. "While teachers or specialists may not be able to clearly differentiate recommended accommodations, their "fall back" approach often seems to be to assign all possible accommodations" (Kopriva et al., 2007, p. 13). If an accommodation incorrectly applied leads to worse test scores than if no accommodations had been applied, then it is even more vital that teachers are educated to recognize which types of accommodations are available, and to know their students so that all appropriate accommodations are provided.

One area of difficulty was that policies sometimes differed between states and districts, which caused confusion when testing. For example, the state might have stricter or more permissive accommodation allowances than the district. Another issue was the documentation of accommodations - who made the decision and who kept track of paperwork - and which types of accommodations were allowed. "The interview data suggested that the variation in the use of accommodations may be due to limited guidelines, limited communication of guidelines, or limited resources" (Wolf, Kao, Rivera, \& Chang, 2012, p. 19). Those classroom teachers who are less informed about either their students or the assessment possibilities tend to provide no benefits to their ELL students by not matching them with their correct supports. If schools or districts were to have clear accommodation guidelines and ensure that the decision-makers had access to them, it would be more likely that students could receive the correct accommodations.

\section{Test translations}

An additional difficulty in considering the types of accommodations that would help ELLs is the variation in test translations. Translations can be difficult, as the test provider must determine if written or spoken translations are most appropriate for the ELL students (Stansfield, 
THE NEBRASKA EDUCATOR, VOLUME 6

2011). Factors affecting this include literacy skill of the ELLs' L1 and L2 as well as the language of instruction and content area being assessed. There is also a perception that providing test translations can also be very expensive, especially when multiple languages are needed. Written translations provide a resource that students can refer back to, but oral translations can be done in advance with the approval of an official source or on-the-spot with the high probability of variation between testing locations. Although more expensive, providing recorded official oral translations of the assessment to schools is more reliable as they limit issues related to pronunciation and fluency of the proctor (Bowles \& Stansfield, 2008). As of 2011, only Ohio, Michigan, and Wisconsin provided recorded oral translations for their state standardized tests in order for students to listen with a recording, but no results were provided as to if those oral translations led to more accurate testing of ELLs' content knowledge (Stansfield, 2011), thus making it an area of future research.

\section{Conclusion}

From reviewing some of the literature as it regarded assessment accommodations in the content areas, there were some key themes that emerged. There were some generalizable results of strategies to modify or teach material that led to greater success on standardized tests. Teachers should recognize that to teach English language learners means they must distinguish between content knowledge and language knowledge. It's difficult to ensure that students have the ability to demonstrate what they know about the subject while accounting for gaps in English. However, if teachers do not acknowledge this, then our ELL students are being placed in disadvantageous assessment situations. Providing scaffolded instruction as well as direct and indirect linguistic supports can help to alleviate this problem. 
THE NEBRASKA EDUCATOR, VOLUME 6

Whether accommodations are determined by the individual teacher or by set policy, it's important to ensure that they are appropriate for the student's English level and L1 level, as emphasized by Kopriva et al.: “Additionally, students who were given no test accommodations scored no differently than those students that received accommodation packages that were incomplete or not recommended, given the students' particular needs and challenges” (2007, p 11). If guidelines to determine the correct types of support are not followed, then the assessment would not be able to accurately reflect what the student is able to accomplish with either their content knowledge or language skills.

This is clearly an area that is open to research, and if a researcher is able to obtain permission to work with teachers at the high school level, there is the potential to investigate 1) which types of assessment modifications are being utilized and 2) which types of modifications are beneficial to ELLs. In addition, further distinctions between content areas and student demographics could also be investigated in order to distinguish assessment modifications that would help subsets of students or subjects while ensuring that English language learners are being tested on similar content compared with native-speaking English students. 
THE NEBRASKA EDUCATOR, VOLUME 6

\section{References}

Bowles, M. \& Stansfield, C.W. (2008). A practical guide to standards-based assessment in the native language. https://ncela.ed.gov/files/rcd/BE024208/A_Practical_Guide.pdf

Bunch, G. C., Shaw, J. M., \& Geaney, E. R. (2010). Documenting the language demands of mainstream content-area assessment for English learners: Participant structures, communicative modes and genre in science performance assessments. Language and Education, 24(3), 185-214. https://doi.org/10.1080/09500780903518986

Dougherty Stahl, K. A., \& Bravo, M. A. (2010). Contemporary classroom vocabulary assessment for content areas. The Reading Teacher, 63(7), 566-578. https://doi.org/10.1598/rt.63.7.4

Education Commission of the States. (2014). What ELL training, if any, is required of general classroom teachers? https://ecs.secure.force.com/mbdata/mbquestNB2?rep=ELL1415

Kopriva, R. J., Emick, J. E., Hipolito-Delgado, C. P., \& Cameron, C. A. (2007). Do proper accommodation assignments make a difference? Examining the impact of improved decision making on scores for English Language Learners. Educational Measurement: Issues and Practice, 26(3), 11-20. https://doi.org/10.1111/j.1745-3992.2007.00097.x

Leith, C., Rose, E., \& King, T. (2016). Teaching mathematics and language to English learners. The Mathematics Teacher, 109(9), 670-678.

Llosa, L., Beck, S. W., \& Zhao, C. G. (2011). An investigation of academic writing in secondary schools to inform the development of diagnostic classroom assessments. Assessing Writing, 16(4), 256-273. https://doi.org/10.1016/j.asw.2011.07.001

Monarrez, A., \& Tchoshanov, M. (2020). Unpacking teacher challenges in understanding and implementing cognitively demanding tasks in secondary school mathematics classrooms. 
THE NEBRASKA EDUCATOR, VOLUME 6

International Journal of Mathematical Education in Science and Technology, 1-17. https://doi.org/10.1080/0020739X.2020.1857860

Office for Civil Rights: U.S. Department of Education. (25 September 2018). Developing programs for English language learners: Lau v. Nichols. Retrieved from https://www2.ed.gov/about/offices/list/ocr/ell/lau.html

Office of Elementary and Secondary Education: U.S. Department of Education. (2002). No Child Left Behind: A desktop reference. https://www2.ed.gov/admins/lead/account/nclbreference/reference.pdf

Oh, S. (2020). Second language learners' use of writing resources in writing assessment. Language Assessment Quarterly, 17(1), 60-84. https://doi.org/10.1080/15434303.2019.1674854

Rivera, C., \& Stansfield, C. W. (2004). The effect of linguistic simplification of science test items on score comparability. Educational Assessment, 9(3-4), 79-105. https://doi.org/10.1080/10627197.2004.9652960

Schleppegrell, M. J. (2007). The linguistic challenges of mathematics teaching and learning: A research review. Reading and Writing Quarterly, 23(2), 139-159. https://doi.org/10.1080/10573560601158461

Shafer Willner, L., Rivera, C., \& Acosta, B. D. (2009). Ensuring accommodations used in content assessments are responsive to English-language learners. The Reading Teacher, 62(8), 696-698. https://doi.org/10.1598/rt.62.8.8

Stansfield, C. W. (2011). Oral translation as a test accommodation for ELLs. Language Testing, 28(3), 401-416. https://doi.org/10.1177/0265532211404191 
THE NEBRASKA EDUCATOR, VOLUME 6

Turkan, S., \& Liu, O. L. (2012). Differential performance by English language learners on an inquiry-based science assessment. International Journal of Science Education, 34(15), 2343-2369. https://doi.org/10.1080/09500693.2012.705046

Uccelli, P., \& Phillips Galloway, E. (2017). Academic language across content areas: Lessons from an innovative assessment and from students' reflections about language. Journal of Adolescent and Adult Literacy, 60(4), 395-404. https://doi.org/10.1002/jaal.553

U.S. Department of Education. (2016) Non-regulatory guidance: English Learners and Title III of the Elementary and Secondary Education Act (ESEA), as amended by the Every Student Succeeds Act (ESSA). https://www.education.ne.gov/wpcontent/uploads/2017/07/essatitleiiiguidenglishlearners92016.pdf

Wolf, M. K., Kao, J. C., Rivera, N. M., \& Chang, S. M. (2012). Accommodation practices for English language learners in states' mathematics assessments. Teachers College Record, $114(3), 1-26$.

Wolf, M. K., Kim, J., \& Kao, J. (2012). The effects of glossary and read-aloud accommodations on English language learners’ performance on a mathematics assessment. Applied Measurement in Education, 25(4), 347-374. https://doi.org/10.1080/08957347.2012.714693 
THE NEBRASKA EDUCATOR, VOLUME 6

\section{Appendix}

Definitions and Acronyms for Second Language Students and Programs

ELL - English Language Learner - A K-12 student who is classified through testing as being in need of English language support in school. Also known as an EL, or English Learner

ELLs - English Language Learners

ESL - English as a Second Language (more commonly used to refer to programs rather than the students)

ESOL - English to Speakers of Other Languages (more commonly used to refer to programs rather than the students)

L1 - First language; also known as a person's native language

L2 - Second language; refers to all languages learned after the first whether actually the second language or a subsequent one

LEP - Limited English Proficient; can be used as a synonym for an English Language Learner, but does not have to be in the K-12 setting or currently receiving English supports

Non-ELL - A student who is not currently classified as an English Language Learner. This may be a native English speaker or a student who was previously classified as an English Language Learner and has exited due to achieving English proficiency

Non-LEP - A person who is proficient in English 